\title{
PENGARUH SISTEM OLAH TANAH DAN PEMUPUKAN N JANGKA PANJANG TERHADAP BIOMASSA KARBON MIKROORGANISME ( $C$-mik) DI RIZOSFER DAN NON-RIZOSFER PADA PERTANAMAN JAGUNG (Zea maysL.)
}

\author{
Ida Susanti, Muhajir Utomo \& Henrie Buchari \\ Jurusan Agroteknologi, Fakultas Pertanian Universitas Lampung \\ Jl. Prof. Soemantri Brodjonegoro, No.1, Bandar Lampung 35145 \\ Email : ida.susanti92@gmail.com
}

\begin{abstract}
ABSTRAK
Dalam bercocok tanam petani biasa menggunakan sistem olah tanah intensif. Olah tanah intensif yang dilakukan secara terusmenerus dapat menimbulkan kerusakan tanah yang mengakibatkan erosi dan menurunnya kadar bahan organik. Sistem Olah Tanah Konservasi (OTK) adalah suatu sistem persiapan lahan yang bertujuan untuk menyiapkan lahan agar tanaman dapat tumbuh dan berproduksi optimum. Selain itu pemberian pupuk nitrogen penting bagi tanaman danmikroorganisme tanah agar dapat terus beraktivitas. Mikroorganisme tanah sangat memegang peranan penting dalam proses yang terjadi didalam tanah terhadap, terutama daerah rizosfer. Penelitian ini bertujuan untuk untuk mengetahui biomassa karbon mikroorganisme (C-mik) di rizosfer dan non-rizosfer pada pertanaman jagung akibat perlakuan sistem pengolahan tanah dan pemupukan N. Penelitian ini dilakukan dengan menggunakan rancangan acak kelompok (RAK) dan di susun secara faktorial (2x2) dengan 4 ulangan. Faktor pertama adalah sistem olah tanah $(\mathrm{T})$ yaitu $\mathrm{T}_{0}=$ TOT (tanpa olah tanah), $\mathrm{T}_{1}=$ OTI (olah tanah intensif), dan faktor kedua adalah pemupukan nitrogen $(\mathrm{N})$ yaitu $\mathrm{N}_{0}=0 \mathrm{~kg} \mathrm{~N} \mathrm{ha}^{-1}, \mathrm{~N}_{1}=100 \mathrm{~kg} \mathrm{~N} \mathrm{ha}^{-1}$. Sampel tanah di ambil pada saat 9 minggu setelah tanam (MST). Data yang diperoleh diuji homogenitasnya dengan uji Barlet dan aditifitasnya dengan Uji Tukey serta dilanjutkan dengan uji BNJ pada taraf $5 \%$.Hasil penelitian menunjukkan bahwa bahwa biomassa karbon mikroorganisme rizosfer dan non rizosfer pada sistem tanpa olah tanah lebih tinggi dari sistem olah tanah intensif. Biomassa karbon mikroorganisme rizosfer dan non rizosfer pada pemupukan $100 \mathrm{~N} \mathrm{~kg} \mathrm{ha}^{-1}$ lebih tinggi dari pemupukan $0 \mathrm{~N} \mathrm{~kg} \mathrm{ha}^{-1}$. Interaksi antara sistem pengolahan tanah dan pemupukan $\mathrm{N}$ untuk biomassa karbon mikroorganisme rizosfer hanya terjadi pada 9 MST, sedangkan pada nonrizosfer tidak terjadi interaksi.
\end{abstract}

Kata kunci : Biomassa karbon mikroorganisme tanah $(C$-mik), pemupukan nitrogen $(\mathrm{N})$, rizosfer, sistem olah tanah konservasi

\section{PENDAHULUAN}

Pertanian di Indonesia biasanya menggunakan sistem olah tanah intensif (OTI) yaitu tanah dicangkul setiap kali bertanam tanpa penggunaan mulsa. Pengolahan tanah ini dilakukan terus menerus, dapat menimbulkan kerusakan tanah yang mengakibatkan erosi dan menurunnya kadar bahan organik. Salah satu upaya untuk mengurangi dampak negatif tersebut adalah cara olah tanah konservasi (tanpa olah tanah (TOT) dan olah tanah minimum (OTM)). Sistem olah tanah konservasi bertujuan untuk menyiapkan lahan agar dapat tumbuh dan berproduksi optimum dan tetap memperhatikan konservasi tanah dan air (Utomo, 1995).

Pemupukan adalah suatu tindakan pemberian unsur hara ke tanah ataupun tanaman yang sesuai dan dibutuhkan agar tanaman tumbuh dan berkembang normal (Pulung, 2005). Nitrogen salah satu unsur hara yang diperlukan untuk pertumbuhan dan perkembangan tanaman secara optimum.Penelitian Niswati, et al (1995) penggunaan pupuk nitrogen secara berkelanjutan dapat meningkatkan populasi mikroorganisme tanah. Hal ini disebabkan unsur $\mathrm{N}$ dapat membantu dalam pembentukan sel tubuh mikroorganisme. Semakin tinggi unsur $\mathrm{N}$ didalam tanah maka total mikroorganisme semakin tinggi.

Menurut Bangun (2002), biomassa karbon mikroorganisme (C-mik) merupakan indeks kesuburan tanah. Ukuran dan aktivistas biomassa mikroorganisme dipengaruhi sejumlah faktor diantaranya ketersediaan C-organik, status hara, kelembaban tanah, jenis tanaman, dan praktek pengolahan tanah. Penerapan OTK dan pemupukan $\mathrm{N}$ dapat meningkatkan biomassa mikroorganisme (C-mik). Hal ini dikarenakan perbedaan 
olah tanah yang mempengaruhi kondisi lingkungan yang kondusif untuk habitat mikroorganisme tanah.

Habitat mikroorganisme tanah berkumpul dan mendapat cadangan makanan yang beragam yaitu di daerah rizosfer. Salam (2012) menyatakan rizosfer adalah volume tanah, air, dan udara serta mikroorganisme yang terikat dekat di sekitar akar tanaman. Secara umum rizosfer dicirikan dengan aktivitas biologinya yang paling tinggi pada tanah mendapat cadangan makanan yang beragam yaitu di daerah rizosfer.

Penelitian ini bertujuan untuk untuk mengetahui biomassa karbon mikroorganisme (C-mik) di rizosfer dan non-rizosfer pada pertanaman jagung akibat perlakuan sistem pengolahan tanah dan pemupukan $\mathrm{N}$

\section{BAHAN DAN METODE}

Penelitian ini dilaksanakan pada bulan Desember 2012 musim ke 43 sampai dengan bulan April 2013 di lahan Politeknik Negeri Lampung. Analisis tanah dilakukan di Laboratorium Jurusan Ilmu Tanah Fakultas Pertanian Universitas Lampung. Penelitian ini dirancang dalam rancangan acak kelompok (RAK) dan disusun secara faktorial $(2 \times 2)$ dengan 4 ulangan. Faktor pertama dalam penelitian ini adalah perlakuan sistem olah tanah $(\mathrm{T})$ yaitu $_{0}=$ tanpa olah tanah, dan $\mathrm{T}_{1}=$ olah tanah intensif dan faktor kedua dalam penelitian ini adalah pemupukan nitrogen $(\mathrm{N})$ yaitu $\mathrm{N}_{0}=0 \mathrm{~kg}$ dan $\mathrm{N}_{1}=100 \mathrm{~kg}$. Pengambilan sampel dilakukan pada 2 tempat, yaitu rizosfer dan non-rizosfer. Dilakukan dengan cara tanah di bor pada 3 titik dengan kedalaman $20 \mathrm{~cm}$ kemudian dikompositkan.Pengambilan sampel tanah dilakukan pada 9 MST. Data yang diperoleh diuji homogenitasnya dengan uji Barlet dan aditifitasnya dengan Uji Tukey. Data dianalisis dengan sidik ragam dan dilanjutkan dengan Uji BNJ 5\%.

Proses pelaksanaan analisis biomassa mikroorganisme yaitu sampel tanah komposit yang diambil pada lahan penelitian diambil sebanyak 10 gram tanah inokulan diikat rapat dalam plastik kemudian dimasukkan ke dalam lemari pendingin. Kemudian diambil tanah lembab (setara dengan 30 gram berat kering oven) ditempatkan dalam gelas beaker $50 \mathrm{ml}$. Tanah dalam beaker tersebut diletakkan dalam desikator untuk difumigasi menggunakan kloroform $\left(\mathrm{CHCl}_{3}\right)$ sebanyak $30 \mathrm{ml}$. Fumigasi dilakukan dengan tekanan 50 $\mathrm{cm} \mathrm{Hg}$ selama 6 kali 5 menit (sampai kloroform mendidih), kemudian diamkan selama 48 jam. Setelah tanah difumigasi selama 48 jam, tanah dibebaskan dari $\mathrm{CHCl}_{3}$ kemudian diberi tekanan di bawah $30 \mathrm{~cm} \mathrm{Hg}$ selama 8 kali 5 menit. Kemudian tanah dimasukkan ke dalam toples berukuran 1 liter yang sudah ada botol film yang berisi $10 \mathrm{ml} \mathrm{KOH} \mathrm{0,5} \mathrm{N}$ dan $10 \mathrm{ml}$ aquades. Tambahkan 10 gram tanah inokulan (tanah segar) yang telah dikeluarkan dari lemari pendingin selama 6 jam ke dalam beaker yang berisi 30 gr tanah yang telah difumigasi. Toples ditutup dengan lakban dan diinkubasi pada suhu $25^{\circ} \mathrm{C}$ selama 10 hari. Kuantitas $\mathrm{C}-\mathrm{CO}_{2}$ yang diserap dalam $\mathrm{KOH} 0,5 \mathrm{~N}$ ditentukan dengan titrasi. Blangko menggunakan 30 gram tanah lembab setara berat kering oven yang tidak difumigasi. Tanah tersebut dimasukkan ke dalam toples berukuran 1 liter beserta $10 \mathrm{ml} 0,5 \mathrm{~N} \mathrm{KOH}$ dan satu botol film berisi $10 \mathrm{ml}$ aquades, tetapi tidak diberikan inokulan.Biomassa karbon mikroorganisme tanah dihitung dengan rumus akhir:

$$
\begin{aligned}
\mathrm{BM}-\mathrm{C}=\mathrm{C}-\mathrm{mik} & =\frac{\left(\mathrm{mg} \mathrm{C}-\mathrm{CO}_{2} \mathrm{~kg}^{-1} 10 \text { hari }\right)_{\text {fumigasi }}-\left(\mathrm{mg} \mathrm{C}-\mathrm{CO}_{2} \mathrm{~kg}^{-1} 10 \text { hari }\right)_{\text {nonfumigas }}}{\mathrm{KC}} \\
& \left(\mathrm{mg} \mathrm{C} \mathrm{kg}^{-1} 10 \text { hari }\right)_{\text {fumigasi }}=\frac{(\mathrm{a}-\mathrm{b}) \times \mathrm{t} \times 120}{\mathrm{n}} \\
& \left(\mathrm{mg} \mathrm{C} \mathrm{kg}^{-1} 10 \text { hari }\right)_{\text {nonfunigas } \mathrm{i}}=\frac{(\mathrm{a}-\mathrm{b}) \times \mathrm{t} \times 120}{\mathrm{n}}
\end{aligned}
$$

Keterangan :

BM-C = C-mik (Biomassa karbon mikroorganisme tanah)

a $\quad=\mathrm{ml} \mathrm{HCl} \mathrm{untuk} \mathrm{tanah} \mathrm{fumigasi}+$ inokulan

$\mathrm{b}=\mathrm{ml} \mathrm{HCl} \mathrm{untuk} \mathrm{kontrol} \mathrm{(kontrol} \mathrm{adalah} \mathrm{inkubasi} \mathrm{tanpa} \mathrm{tanah)}$

$\mathrm{t} \quad=$ normalitas $\operatorname{HCl}(0,1)$

$\mathrm{n} \quad=$ hari

$\mathrm{kc} \quad=0,41$ 


\section{HASIL DAN PEMBAHASAN}

Biomassa karbon mikroorganisme di rizosfer. Hasil analisis ragam (Tabel 1) menunjukkan bahwa sistem olah tanah, perlakuan pemupukan nitrogen, dan interaksi keduanya menunjukkan pengaruh nyata terhadap C-mik. Hal ini diduga karena pada pengolahan tanah TOT tanah tidak diolah dan serasah tanaman dijadikan sebagai mulsa pada lapisan permukaan tanah. Oleh karena itu, pada sistem TOT memiliki total C-mik yang lebih tinggi bahan organik tanahnya yang berfungsi sebagai sumber utama ketersediaan bahan makanan bagi mikroorganisme tanah yang berasal dari mulsa tersebut. Penambahan unsur hara $\mathrm{N}$ di dalam tanah akan menyebabkan jumlah biomassa mikroorganisme tanah akan meningkat. Penambahan nitrogen dalam tanah akan diadsorpsi oleh mikroorganisme dan disintesis di dalam tubuhnya sehingga dapat membentuk jaringan tubuh dan memacu pertumbuhan mikroorganisme untuk melakukan proses dekomposisi bahan organik. Sedangkan pada perlakuan tanpa pemupukan N, karena tidak adanya penambahan unsur $\mathrm{N}$ sehingga aktivitas mikroorganisme menurun (Bangun, 2002).

Interaksi sistem olah tanah dan pemupukan nitrogen. Pada pengamatan 9 MST (Tabel 2) terdapat interaksi yang menunjukkan C-mik tertinggi dicapai pada kombinasi sistem TOT dengan pemupukan $100 \mathrm{~kg} \mathrm{~N}$ ha $^{-1}$, sedangkan pada kombinasi lainnya tidak berbeda nyata. Hal ini diduga penggunaan sistem TOT memberikan pengaruh yang besar terhadap kondisi tanah yaitu dapat memperbaiki aerasi tanah, $\mathrm{pH}$, dan C-organik sehingga mikroba dapat tumbuh dan berkembang dengan baik. Pemberian nitrogen kedua memberikan energi untuk mikroorganisme, pemupukan $\mathrm{N}$ ke dalam tanah mempengaruhi ketersedian $\mathrm{N}$, dan dapat digunakan oleh mikroorganisme tanah.

Biomassa karbon mikroorganisme di nonrizosfer. Hasil analisis ragam (Tabel 3) pada saat 9 MST menunjukkan bahwa sistem olah tanah, pemupukan $\mathrm{N}$, dan interaksi keduanya tidak berpengaruh nyata terhadap mikroorganisme (C-mik). Hal ini diduga aktivitas mikroorganisme yang lambat karena rendahnya

Tabel 1. Hasil analisis ragam pengaruh sistem olah tanah dan pemupukan nitrogen terhadap C-mik di rizosfer pada tanaman jagung.

\begin{tabular}{cc}
\hline Sumber Keragaman & Waktu Pengamatan (9 MST) \\
\hline $\mathrm{T}$ & $*$ \\
$\mathrm{~N}$ & $*$ \\
$\mathrm{~T} \times \mathrm{N}$ & $*$
\end{tabular}

Keterangan $: *$ berpengaruh nyata pada taraf á $=5 \%, \mathrm{~T}=$ olah tanah, $\mathrm{N}=$ pupuk, $\mathrm{TN}=$ interaksi olah tanah dan pupuk N.

Tabel 2. Pengaruh interaksi sistem olah tanah dan pemupukan nitrogen $(\mathrm{N})$ pada pertanaman jagung (Zea mays L.) terhadap C-mik di rizosfer pada saat 9 MST.

\begin{tabular}{|c|c|c|c|}
\hline \multirow{2}{*}{ Sistem Olah Tanah } & \multicolumn{2}{|c|}{ Pemupukan Nitrogen } & \multirow{2}{*}{ BNJ 0,05} \\
\hline & $0 \mathrm{~kg} \mathrm{~N} \mathrm{ha}^{-1}$ & $100 \mathrm{~kg} \mathrm{~N} \mathrm{ha}^{-1}$ & \\
\hline \multicolumn{4}{|c|}{ 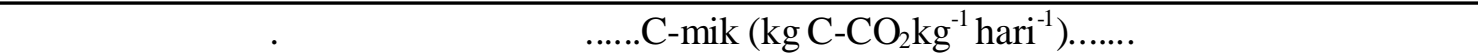 } \\
\hline Tanpa Olah Tanah & 109,8 a & $126,3 \mathrm{~b}$ & \multirow{4}{*}{4,9} \\
\hline$(\mathrm{TOT})$ & A & B & \\
\hline Olah Tanah Intensif & $112,7 \mathrm{a}$ & 114,6 a & \\
\hline$(\mathrm{OTI})$ & A & A & \\
\hline
\end{tabular}

Keterangan : Angka yang diikuti oleh huruf yang sama tidak berbeda nyata dengan uji BNJ pada taraf nyata 5\%. Huruf kecil merupakan notasi untuk membedakan pada baris yang sama. Huruf kapital merupakan notasi untuk membedakan pada kolom yang sama. 
Tabel 3. Ringkasan analisis ragam pengaruh sistem olah tanah dan pemupukan nitrogen terhadap C-mik di nonrizosfer pada tanaman jagung.

\begin{tabular}{cc}
\hline Sumber Keragaman & Waktu Pengamatan (9 MST) \\
\hline $\mathrm{T}$ & tn \\
$\mathrm{N}$ & tn \\
$\mathrm{T} \times \mathrm{N}$ & tn \\
\hline
\end{tabular}

Keterangan : $\mathrm{tn}=$ tidak berpengaruh nyata pada taraf $\mathrm{a}=5 \%, \mathrm{~T}=$ olah tanah, $\mathrm{N}=$ pupuk, $\mathrm{T} \times \mathrm{N}=$ interaksi olah tanah dan pupuk $\mathrm{N}$.

nitrogen yang ada didalam tanah sehingga mikroba tidak peka dan akibatnya aktivitasnya berlangsung lambat. Aktivitas mikroorganisme di dalam tanah atau nonrizosfer berbeda dengan aktivitas mikroorganisme di rizosfer. Didaerah rizosfer, mikroorganisme mendapatkan energi untuk kehidupannya, karena akar selain berperan dalam penyerapan unsur hara akar juga dapat menyerap air dan hara dari tanah di sekelilingnya sehingga menyebabkan penurunan dan penimbunan ion serta akar mengeksudasi ion menyebabkan perubahan pH dan potensial redoks tanah (Handayanto, 2007). Dengan demikian aktivitas biologi yang terjadi di rizosfer lebih baik dibandingkan non-rizosfer.

\section{KESIMPULAN}

Dari hasil penelitian dapat disimpulkan bahwa Biomassa karbon mikroorganisme daerah rizosfer pada perlakuan sistem tanpa olah tanah (TOT) lebih tinggi dibandingkan olah tanah intensif (OTI). Biomassa karbon mikroorganisme daerah rizosfer pada perlakuan pemupukan nitrogen dengan dosis $100 \mathrm{~kg} \mathrm{~N}^{-1}$ lebih tinggi dari pemupukan $0 \mathrm{~kg} \mathrm{~N} \mathrm{ha}^{-1}$. Terjadi interaksi antara sistem olah tanah dan pemupukan N. Biomassa karbon mikroorganisme daerah non-rizosfer pada perlakuan sistem tanpa olah tanah (TOT) lebih tinggi dibandingkan olah tanah intensif (OTI). Biomassa karbon mikroorganisme daerah non-rizosfer pada pemupukan nitrogen dengan dosis $100 \mathrm{~kg} \mathrm{~N}^{-1}$ lebih tinggi dari pemupukan $0 \mathrm{~kg} \mathrm{~N} \mathrm{ha}^{-1}$. Tidak terjadi interaksi antara sistem olah tanah dan pemupukan $\mathrm{N}$.

\section{DAFTAR PUSTAKA}

Bangun, I. 2002. Pengembangan Metode Penetapan Biomassa Karbon Mikroorganisme Tanah (C-mik) dengan Menggunakan Ultrasonik Processor. Skripsi. Institut Pertanian Bogor.

Handayanto, E. dan K. Hairiah. 2007. Biologi Tanah. (Ekologi dan MakrobiologiTanah). PTRaja Grafindo Persada. Jakarta. $166 \mathrm{hlm}$.

Niswati, A., M. Utomo, dan S.G Nogroho. 1995. Dampak Mikrobiologi Tanah Penerapan Teknik Tanpa Olah Tanah dengan Herbisida Amino Glifosfat Secara Terus-menerus pada Lahan Kering di Lampung. Laporan Penelitian DP3M. Unila.

Pulung, M. A. 2005. Kesuburan Tanah.Universitas Lampung. Bandar Lampung. $287 \mathrm{hlm}$. (Buku Ajar).

Salam, A.K. 2012. Ilmu Tanah Fundamental. Global Madani Press. Bandar Lampung.

Setyo, N. 2011. Peran Olah Tanah Konservasi dan Pemupukan Nitrogen terhadap Peningkatan Biomassa Karbon Mikroorganisme (C-mik pada Lahan Kedelai (Glycine max L. ) di Politeknik Negeri Almpung. Skripsi Fakultas Pertanian Universitas Lampung. Bandar Lampung.

Utomo, M. 1995. Kekerasan Tanah dan Serapan Hara Tanaman Jagung pada Konservasi Jangka Panjang. J. Tanah Trop. 1:1-7. 